Mental Capacity and Safeguarding training is mandatory for most staff and yet human rights, which are the foundation for both, has been overlooked.

To meet this gap in practice, Sue Ryder worked with the British Institute of Human Rights to develop a Practitioners Guide. Following the learning from the demise of the Liverpool Care Pathway, a grant was secured from the Burdett Trust for Nursing to deliver a three year training programme. Aim To educate and empower the workforce to feel more confident in embracing human rights as an integral component to end of life care, by building on existing knowledge and experience, increasing awareness of how human rights can be used to aid decision making and ensure human rights values are at the heart of personalised care.

Methods Sue Ryder is delivering a three tiered training programme: half day workshops for the non-registered workforce; 1 day workshops for the registered workforce; two-day workshops for train the trainers to enable sustainability. Nottingham Centre for the Advancement of Research in End of Life Care will evaluate the training using a longitudinal mixed methods design, using pre and post training confidence questionnaires and interviews.

Results We have delivered four workshops and educated 49 practitioners to May. A further 26 workshops are planned. We project to have educated 444 practitioners, including 24 trainers, by the end of 2017. Qualitative feedback has been overwhelmingly positive.

Conclusion Everyone working in end of life care should understand their human rights responsibilities in order to deliver personalised care. The Sue Ryder training programme will increase practitioners understanding and confidence to fulfil their duty.

\section{P-152 THE LEGACY OF THE NOTHERN IRELAND CONFLICT IN PALLIATIVE CARE}

Brendan O'Hara. All Ireland Institute of Hospice and Palliative Care, Dublin, Ireland

\subsection{6/bmjspcare-2017-hospice.177}

Background Understanding the impact of the Northern Ireland 'Troubles'/'conflict' on a particular area of health care - palliative care - which has received little, if any, previous research focus. The research was carried out for a dissertation submitted in partial fulfilment for the degree of Master of Philosophy.

Aim(s) To investigate how the legacy of the Northern Ireland conflict may be encountered by professionals providing palliative care - to those they are caring for who may have been directly/indirectly affected (victims/survivors) and those involved in inflicting damage, death and/or injury. To investigate how the distinct context of Northern Ireland has impacted on palliative care practice.

Method Interviews were carried out with nine professionals with experience and interest in the provision of support to people with palliative care needs. Participants reflected experience across a wide geography of Northern Ireland including the region's two major cities, four of the region's five health and social care trust areas, and four of the five inpatient hospice facilities. Participants included: three nurses; two doctors; a social worker; a chaplain; a complementary therapist and a welfare officer.
Results This research opened up a dialogue between the disciplines of peacebuilding and palliative care. The language of legacy, narrative, life story and peacebuilding is one which the palliative care community understands.

The impact of the Troubles has had an effect on the delivery of palliative care, through the attitudes and influences on those who provide the care and those they care for.

Conclusion The influences of the religious divide, the silencing, and the traumas of the past are not something that the care-giver is apart from - they are very much influenced by them. The sensitivities around the Catholic/Protestant divide, the silencing, and restricting opportunities to talk about 'Troubles'-related trauma, could prevent people from having appropriate palliative care.

\section{P-153 STOPPING TRAFFIC}

Beth Ward. Demelza Hospice Care for Children, Sittingbourne, Kent, UK

10.1136/bmjspcare-2017-hospice. 178

The United Kingdom is one of the most prominent destination countries for people to be trafficked to in Europe. An estimated 20000 people are trafficked into (and throughout) the UK every year, with the majority of victims coming from, arguably, the poorest countries. This presentation outlines the case of a baby (aged two days) who was referred to a children's hospice for end of life care. Within the context of the direct work, it became apparent that the mother had been trafficked into the UK and had experienced periods of homelessness. The children's hospice social work team worked intensively to seek support for this mother, but due to high service demand, and the mother's questionable residency status, no statutory organisation was willing to engage. The NSPCC helpline recommended the Salvation Army, a Christian church and registered charity and this partner charity offered an assessment visit by their Anti-Human Trafficking Team's First Responder Co-ordinator and plans were subsequently put in place for the team to take on the supporting role after the baby's death. As well as focusing on safeguarding this extremely vulnerable family unit, it was essential that this mother had the opportunity to bond with her baby and to, albeit briefly, positively experience motherhood. The baby died peacefully, aged seven weeks. Pre-death planning had clarified the family's customs and rituals, which dictated that the parents did not attend the funeral and therefore, two members of the children's hospice team, together with two representatives from the Salvation Army were present, as a mark of respect. A year on, the mother continues to receive concerted support from the partnership charity, enabling her to preserve her dignity, reflect, recover and rebuild her life.

\section{P-154 THE VALUE OF SILENCE IN END-OF-LIFE SPIRITUAL CARE: CONNEXION, COMPANIONSHIP, POTENTIAL FOR CHANGE}

Lynn Bassett, Amanda F Bingley, Sarah G Brearley. Lancaster University, Lancaster, UK

\subsection{6/bmjspcare-2017-hospice. 179}

Background At the end of life silence seems to take increasing prominence in encounters between professional caregivers, patients and their family members but its value as an element 